\title{
DERRAME PERICÁRDICO COMO PRIMEIRA MANIFESTAÇÃO DA TIREOIDITE DE HASHIMOTO
}

Pôster

Autores deste trabalho:

Ingrid Lacerda Pessoa: Hospital Infantil Cândido Fontoura

Rafaela Oliveira Tavares : Hospital Infantil Cândido Fontoura

Andressa Clemente Mesquita : Hospital Infantil Cândido Fontoura

João Pedro de Figueiredo Jordão Furtado de Mendonça: Hospital Infantil Cândido Fontoura

Maryana Beltrão de Carvalho: Hospital Infantil Cândido Fontoura

Raquel Fontana: Hospital Infantil Cândido Fontoura

Pedro Teles de Mendonça Neto: Hospital Infantil Cândido Fontoura

Mariana Aparecida Brunossi Moura Proença: Hospital Infantil Cândido Fontoura

Área do Trabalho: Pediatria

Data da submissão: $31 / 07 / 2018$ às $13: 40$

\section{Justificativa}

A Tireoidite de Hashimoto (TH) é uma doença autoimune considerada causa relevante de bócio e hipotireoidismo adquirido em crianças e adolescentes. Tem incidência 4 a 5 vezes maior no sexo feminino e sua prevalência aumenta com a idade, sendo rara abaixo dos 4 anos e mais frequente na adolescência. Os principais sintomas da patologia são bócio, baixa estatura, ganho de peso e outros sintomas de hipotireoidismo. Além disso, tem sido associada a doenças autoimunes como diabetes, doenças reumáticas, doença celíaca.

\section{Objetivo(s)}

Relatar caso clínico de uma paciente que iniciou o quadro de $\mathrm{TH}$ com derrame pericárdico (DP).

\section{Método(s)}

Levantamento de dados através da análise de prontuários.

\section{Resultado(s)}

R.X.B, 9 anos, sexo feminino, estudante, natural e procedente de São Paulo, com quadro de tosse seca há aproximadamente 25 dias, com piora noturna, que evoluiu para desconforto respiratório em repouso; associado, apresentou um pico febril isolado. Fez tratamento para amigdalite com azitromicina por 5 dias, sem melhora. Procurou serviço médico, sendo realizada radiografia de tórax que demonstrou aumento de área cardíaca, sem acometimento pulmonar. Solicitado ecocardiograma que evidenciou derrame pericárdico laminar. Optado por internação para investigação do quadro. Solicitado exames laboratoriais, incluindo provas reumatológicas com Fator anti-núcleo reagente, outros anticorpos negativos e provas tireoidianas, com aumento de Hormônio tireoestimulante (TSH), anticorpo 


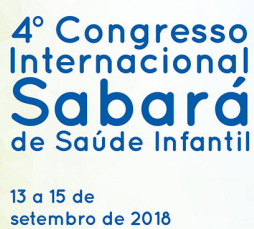

13 a 15 de
setembro de 2018
Hotel Maksoud Plaza
Alameda Campinas, 150
Säo Paulo- Brosil

antiperoxidase e anticorpo antitireoglobulina elevados. Diagnosticada com TH e introduzido levotiroxina. Realizada também investigação de tuberculose com Prova Tuberculínica e Tomografia de tórax, ambos dentro da normalidade. Manteve-se afebril durante internação, sem alterações ao exame físico. Recebeu alta hospitalar após 1 semana, em uso de levotiroxina, com encaminhamento ao ambulatório de endocrinologia e reumatologia para seguimento.

\section{Conclusão (ões)}

A TH é uma condição com bom prognóstico, principalmente se diagnosticada precocemente e instituído tratamento adequado. Deve-se atentar para os sintomas clássicos, porém seu quadro pode iniciar com achados incomuns, podendo ainda haver associação com outras doenças autoimunes. 